\title{
Theoretical Study of Hydrogen Bond Formation in Four Rare Sugars: Gulose, Allose, Altrose, and Talose
}

Zahrabatoul Mosapour Kotena ( $\square$ zahrabatool2@gmail.com )

Department of Chemistry, Faculty of Science, University of Malaya, 50603 Kuala Lumpur, Malaysia https://orcid.org/0000-0002-9719-5742

Mozhan Razi

Azad University: Islamic Azad University

Sara Ahmadi

Azad University: Islamic Azad University

\section{Research Article}

Keywords: Hydrogen bond, Rare sugars, Gulose, Allose, Altrose, Talose

Posted Date: June 8th, 2021

DOl: https://doi.org/10.21203/rs.3.rs-555471/v1

License: (a) (1) This work is licensed under a Creative Commons Attribution 4.0 International License. Read Full License 


\title{
Theoretical Study of Hydrogen Bond Formation in Four Rare Sugars: Gulose, Allose, Altrose, and Talose
}

\author{
Zahrabatoul Mosapour Kotena ${ }^{1 a *}$, Mozhan Razi $^{b}$, Sara Ahmadi ${ }^{c}$ \\ ${ }^{a}$ Department of Chemistry, Faculty of Science, University of Malaya, 50603, Kuala Lumpur, Malaysia \\ ${ }^{b}$ Department of Agricultural Science \& Food Industries, Science \& Research Branch, Islamic Azad \\ University, Tehran, Iran \\ ${ }^{c}$ Department of Chemistry, Firoozabad Branch, Islamic Azad University, Firoozabad, Iran
}

\begin{abstract}
Rare sugars are monosaccharides with tremendous potential for applications in pharmaceutical, cosmetics, nutraceutical, and flavors industries. The four rare sugars, including; gulose, allose, altrose and talose are stereoisomers that are different in the hydroxyl group orientation (axial or equatorial) on the $\mathrm{C}_{2-4}$ atoms. The DFT, AIM, and, NBO calculations were used to probe the probability of formation of internal H-bonds in four rare sugars. The AIM analysis identified that altrose and talose can form three predominantly intramolecular H-bonds, whereas gulose and allose revealed one and two H-bonds, respectively and these normal intramolecular $\mathrm{H}$-bonds are mostly closed-shell interactions. The theoretical calculated $\mathrm{O}-\mathrm{H}$ stretching FT-IR vibrational frequencies confirmed that the intramolecular H-bonds shifted toward low frequencies in comparison to the free hydroxyl group, which caused the red-shift. Also, the lowest IR frequency in each sugar was related to the structure with the highest stabilization energy and the most strongest intramolecular H-bonds.
\end{abstract}

Keywords: Hydrogen bond, Rare sugars, Gulose, Allose, Altrose, Talose

*Corresponding author:

Tel.: +98-9173616577

aE-mail address: zahrabatool2@ gmail.com,

${ }^{1}$ Department of Chemistry, Sharif University \& Technology, P.O. Box 11365-9516, Tehran, Iran,

${ }^{1}$ E-mail address: zahrabatool2@ sharif.edu 


\section{Introduction}

Rare sugars are monosaccharides with various known biological functions and tremendous potential for applications in pharmaceutical, cosmetics, nutraceuticals, and flavors industries [1-5]. Some rare sugars are used as building blocks for synthesizing nucleotide analogs, which are important as antiviral and anticancer agents. Moreover, due to their immunosuppressive properties, they are used as anti-inflammatory agents [6]. Among different monosaccharides, glucose, galactose, and mannose are abundant in Nature, while gulose, allose, altrose, and talose existing in very small amounts in Nature [7]. Rare sugars have exciting characteristics. They have lower calories than traditional sugars such as sucrose, fructose, glucose, or lactose. The small amount of these sugars makes their separation from the primary sources economically unprofitable. Therefore, inevitable biological processes such as fermentation or enzyme conversion are used to produce these compounds. The studies of rare sugars were limited due to the lack of methods to produce these sugars on a bulk scale until Izumori's group have developed a new methodology for rare sugars productions [8].

Allose occurs as a 6-O-cinnamyl glycoside in the leaves of the African shrub Protea rubropilosa and also in tissues of some plants such as rice [9]. It is soluble in water but practically insoluble in methanol [10]. D-allose has various biological functions, such as antitumor, anti-inflammatory, anti-oxidative, and immunosuppressant activities [11]. D-altrose is an unnatural monosaccharide that is soluble in water [12]. Gulose is another rare monosaccharide in Nature. It has been found in archaebacteria and eukaryotes [13]. Rare sugars such as; $\beta-\mathrm{D} /$ gulose, allose, altrose, and talose contain multiple chiral carbons, and their hydroxyl groups orientations are different (axial/equatorial). These sugars are isomeric molecules having the same molecular formula and sequence of bonded atoms but differ in spatial orientations. Although their only difference is in the hydroxyl groups orientation (axial or equatorial) on the $\mathrm{C}_{2}, \mathrm{C}_{3}$, and $\mathrm{C}_{4}$, this small difference has caused many different physico-chemical properties such as different melting and boiling points [14]. Figure 1 shows the orientation (axial and equatorial) of different hydroxyl groups on $\mathrm{C}_{2}, \mathrm{C}_{3}$, and $\mathrm{C}_{4}$ atoms in several rare sugars, including gulose, allose, altrose, and, talose which are $\beta$-D-anomer. It is worth mentioning that these sugars are stereoisomers, which are epimers to each other.

The hydrogen bond (H-bond) is defined as $\mathrm{X}-\mathrm{H}$...Y interaction, where $\mathrm{X}-\mathrm{H}$ is the typical covalent bond being the proton donating moiety and $\mathrm{Y}$ is a proton accepting center. The $\mathrm{X}$ and $\mathrm{Y}$ are electronegative atoms such as $\mathrm{O}, \mathrm{N}$, and $\mathrm{F}$. The $\mathrm{H}$-bond is a weak attraction with a binding strength less than one-tenth that of a regular covalent bond [16]. Generally, the H-bond energy value for weak H-bond is as low as 0.24 to 0.28 kcal.mol ${ }^{-1}$, although it could reach a maximum of $38 \mathrm{kcal}^{\mathrm{mol}}{ }^{-1}$. On average, the H-bonds are fall in the

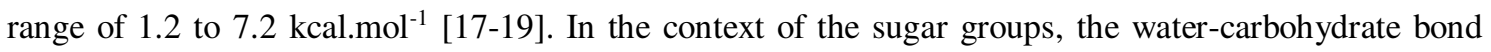
energies are in the range of approximately 3.34-6.45 $\mathrm{kcal}^{\mathrm{mol}}{ }^{-1}$. The H-bonds, specifically intramolecular H-bonds have a strong effect on the physico-chemical properties and self-assembly behavior of the biomolecules. They could participate in the essential vital phenomena either singly or as intricate networks conveying structural and thermodynamic cooperativity [20]. In biology, H-bond is responsible for the formation and functionality of the cell membranes to help the proteins and nucleic acids form and maintain 
specific shapes [21, 22]. According to Lipinski's rule [23], five of the majority of orally active drugs tend to have about five $\mathrm{H}$-bond as donors and ten $\mathrm{H}$-bonds as acceptors to the design of drugs.

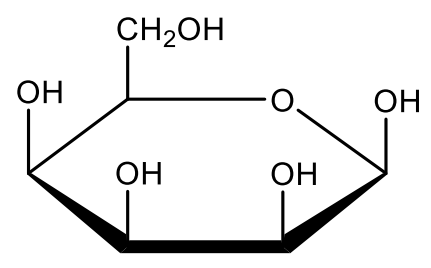

$\beta$-Talose

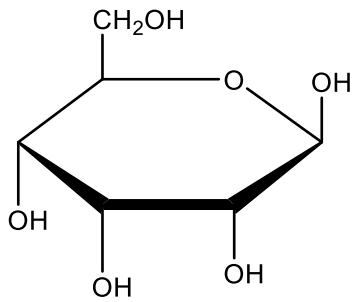

$\beta$-Allose

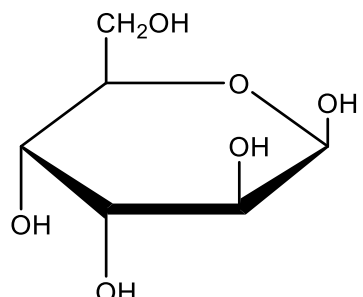

$\beta$-Altrose

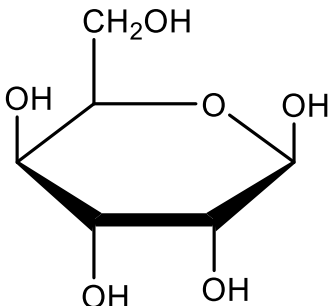

$\beta$-Gulose

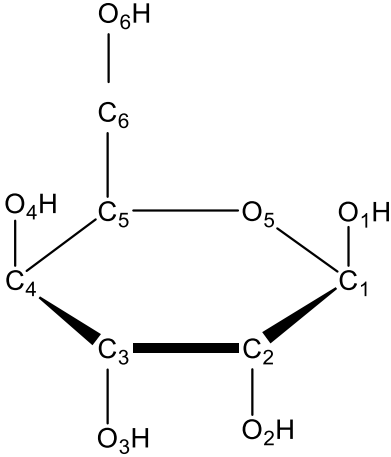

${ }^{\mathrm{a}} \beta-$ Gulose

Figure.1 Schematic view of molecular structures of gulose, allose, altrose, and talose sugars. ${ }^{\text {aThe }}$ IUPAC naming convention for carbohydrates has been used for labeling the atoms [15].

Several theoretical methods have been used to investigate the structural and electronic properties of carbohydrate sugars to understand the nature of H-bonds interactions [24-28]. The present study aims to investigate the $\mathrm{H}$-bonds formation and the orientation effects of five hydroxyl groups in the four rare sugars theoretically. To achieve this goal, density functional theory (DFT) was used for optimizing the equilibrium geometry of the above-mentioned sugars. The atoms in molecules (AIM) approach [29] was used to enhance our understanding of the nature of the H-bond. Useful parameters such as electron density $\rho(r)$ at the bond critical point (BCP) and its Laplacian $\nabla^{2} \rho(r)$ were used to estimate the H-bonds' strength [30]. The natural bond orbital [31,32] analysis of the H-bond was applied to analyze the charge transfer energy during the H-bonds interaction in these rare sugars. Furthermore, the H-bond effects on the $\mathrm{OH}$ stretching frequency of these rare sugars were calculated.

\section{Computational details}

Three methods of DFT, AIM, and NBO have been used to investigate the role of the intra-molecular Hbond interactions in four rare sugars, including gulose, allose, altrose, and talose. The lowest-energy conformers of each sugar were explored at the relative energy range of $0-10\left(\mathrm{kcal}^{\left.-\mathrm{mol}^{-1}\right)}\right.$ using the Merck Molecular Force Field (MMFF) in SPARTAN 14 software [33]. Afterward, the most stable conformers were optimized based on Backe's three-parameter hybrid functional [34], together with Lee-Yang-Parr correlation functional (B3LYP) of the density functional theory (DFT) with 6-31G* basis set in Gaussian 09 [35] package. As the energy ordering changes between MMFF and DFT, the lowest energy of MMFF conformers at the relative energy range of 1-3 $\left(\mathrm{kcal}^{\mathrm{mol}}{ }^{-1}\right)$ were selected for DFT optimization. For instance, from 75 gulose conformers obtained at the relative energy from 0 to $10\left(\mathrm{kcal}^{\mathrm{mol}}{ }^{-1}\right)$ using MMFF, 
just five gulose conformers were in the energy range of 1-3 $\left(\mathrm{kcal}^{\mathrm{mol}}{ }^{-1}\right)$, and these five conformers of gulose has been selected for the DFT optimization. The excellent performance of the B3LYP method for describing sugar isomers has been discussed in previous publications [36, 37]. It has been extensively used to study carbohydrate systems. Momany et.al calculated the geometry optimization of carbohydrates such as $\alpha$ /B-D-glucopyranose [38], $\alpha$-/ $\beta$-D-mannopyranose [36] and, $\alpha$-/ $/$-D-galactopyranose [39] using the B3LYP method. The absence of negative frequency in normal mode analysis proved each of the optimized structures is located at a stable minimum point of the potential energy surface (PES).

The structural and electronic properties such as electron density and Laplacian of the electron density at the bond critical point (BCP) of the formed H-bond were calculated using the theory of atoms in molecules (AIM) proposed by Bader [40, 41] with the AIM 2000 software [42]. The natural bond orbital (NBO) analysis was performed using NBO 3.1 package [43] as implemented in the Gaussian 09 software at the same method and basis set in order to investigate the nature of intramolecular interactions of these four rare sugars. Furthermore, the $\mathrm{OH}$ stretching frequencies (FT-IR spectra) were calculated for these rare sugars.

\section{Results and Discussions}

\section{Energies and geometry optimization}

Table 1 summarizes the bond length, bond angle, and relative energy for gulose, allose, altrose, and talose sugars. There are five $\mathrm{OH}$ groups including; $\left(\mathrm{HO}_{1}, \mathrm{HO}_{2}, \mathrm{HO}_{3}, \mathrm{HO}_{4}\right.$, and $\left.\mathrm{HO}_{6}\right)$ which behave like the $\mathrm{H}-$ bond donors in the formation of intramolecular $\mathrm{H}$-bond; and six oxygen atoms acting as $\mathrm{H}$-bond acceptors in the rare sugar structures (see Figure 1). The average covalent bond lengths (H-O) of five hydroxyl groups for selected rare sugars are about $0.98 \pm 0.01(\AA)$. While, the intramolecular H-bond lengths $(\mathrm{O} \ldots \mathrm{H})$ formed in these sugars are between 1.79 to $2.20(\AA)$, and the bond angles are in the range of $113-144^{\circ}$. The best criteria for H-bond is the distance of less than $3.2(\AA)$ between donor and acceptor [16]. On the other hand, the bond lengths in carbohydrates are in the range of 1.8-2.6 ( $\mathrm{\AA})$ [44], which specifically are 1.50-2.22 ( $)$

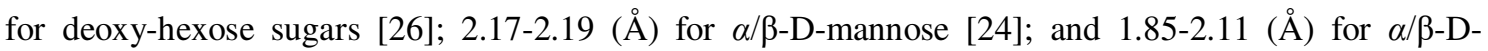
glucopyranose and $\alpha / \beta$-D-galactopyranose [45]. Accordingly, our calculated results are comparable with those reported in the references [24, 26, 44-46].

According to Table 1, the strongest intramolecular $\mathrm{H}$-bonds are related to $\mathrm{O}_{2} \ldots \mathrm{HO}_{4}$ bond in talose and $\mathrm{O}_{6 . .} . \mathrm{HO}_{4}$ bond in gulose with the smallest bond lengths of $1.79 \AA$ and $1.87 \AA$ and the highest bond angles of $143^{\circ}$ and $144^{\circ}$, respectively. The obtained results for talose shown that the intramolecular $\mathrm{O}_{2} \ldots \mathrm{HO}_{4}$ bond is stronger than $\mathrm{O}_{4} \ldots \mathrm{HO}_{6}$ and $\mathrm{O}_{1} \ldots \mathrm{HO}_{2}$ bonds. The intramolecular $\mathrm{O}_{4} \ldots \mathrm{HO}_{6}$ bond is stronger than $\mathrm{O}_{3} \ldots \mathrm{HO}_{2}$ bond in allose due to bond length and bond angle. Whereas three intramolecular H-bonds in altrose are almost the same.

The relative energies values for gulose, allose, altrose and talose are $-431058\left(\mathrm{kcal}^{\mathrm{mol}}{ }^{-1}\right),-431050$ $\left(\mathrm{kcal} . \mathrm{mol}^{-1}\right),-431051\left(\mathrm{kcal} \cdot \mathrm{mol}^{-1}\right)$ and $-431056\left(\mathrm{kcal}^{\mathrm{mol}}{ }^{-1}\right)$, respectively. It was found that talose with three intramolecular H-bonds is the most stable in the last three rare sugars. In comparison between talose and gulose, gulose with one intramolecular H-bond is more stable. This can be related to the free rotation of the 
$\mathrm{HO}_{6}$ group on $\mathrm{C}_{6}$ which leads to the formation of the more stable $\left(\mathrm{O}_{6} \ldots \mathrm{HO}_{4}\right)$ intramolecular $\mathrm{H}$-bond. Whilst, the $\mathrm{HO}_{1}, \mathrm{HO}_{2}, \mathrm{HO}_{3}$ and, $\mathrm{HO}_{4}$ groups in talose are connected to the $\mathrm{C}$ atom of the sugar ring. These dependencies will be confirmed by AIM, NBO, and FT-IR results in the next sections.

Table 1. The relative energies $E\left(\mathrm{kcal}_{\mathrm{m}} \mathrm{mol}^{-1}\right)$, intramolecular H-bond distance $\left(r_{\mathrm{X} . . \mathrm{H}}\right)(\AA \hat{)})$ and bond angle in degree $(\mathrm{X} . . \mathrm{H}-\mathrm{Y})$ of selected rare sugars at $\mathrm{B} 3 \mathrm{LYP} / 6-31 \mathrm{G} *$ level of theory.

\begin{tabular}{|c|c|c|c|}
\hline Sugars & $\mathrm{E}\left(\mathrm{kcal}^{\left.\mathrm{m} \mathrm{mol}^{-1}\right)}\right.$ & $r_{\mathrm{X} \ldots \mathrm{H}}(\AA \AA)$ & X...H-Y $\left({ }^{\circ}\right)$ \\
\hline Gulose & -431058 & $\mathrm{O}_{6} \ldots \mathrm{HO}_{4}=1.87$ & $\mathrm{O}_{6 .} . . \mathrm{HO}_{4}-\mathrm{O}_{4}=144$ \\
\hline Allose & -431050 & $\begin{array}{l}\mathrm{O}_{3} \ldots \mathrm{HO}_{2}=2.13 \\
\mathrm{O}_{4} \ldots \mathrm{HO}_{6}=2.01\end{array}$ & $\begin{array}{l}\mathrm{O}_{3} \ldots \mathrm{HO}_{2}-\mathrm{O}_{2}=113 \\
\mathrm{O}_{4} \ldots \mathrm{HO}_{6}-\mathrm{O}_{6}=138\end{array}$ \\
\hline Altrose & -431051 & $\begin{array}{l}\mathrm{O}_{1} \ldots \mathrm{HO}_{2}=2.11 \\
\mathrm{O}_{3} \ldots \mathrm{HO}_{4}=2.20 \\
\mathrm{O}_{4} \ldots \mathrm{HO}_{6}=2.10\end{array}$ & $\begin{array}{l}\mathrm{O}_{1} \ldots \mathrm{HO}_{2}-\mathrm{O}_{2}=114 \\
\mathrm{O}_{3} \ldots \mathrm{HO}_{4}-\mathrm{O}_{4}=112 \\
\mathrm{O}_{4} \ldots \mathrm{HO}_{6}-\mathrm{O}_{6}=128\end{array}$ \\
\hline Talose & -431056 & $\begin{array}{l}\mathrm{O}_{1} \ldots \mathrm{HO}_{2}=2.14 \\
\mathrm{O}_{2} \ldots \mathrm{HO}_{4}=1.79 \\
\mathrm{O}_{4} \ldots \mathrm{HO}_{6}=1.89\end{array}$ & $\begin{array}{l}\mathrm{O}_{1} \ldots \mathrm{HO}_{2}-\mathrm{O}_{2}=112 \\
\mathrm{O}_{2} \ldots \mathrm{HO}_{4}-\mathrm{O}_{4}=143 \\
\mathrm{O}_{4} \ldots \mathrm{HO}_{6}-\mathrm{O}_{6}=141\end{array}$ \\
\hline
\end{tabular}

\section{Atoms in Molecules (AIM) analysis}

AIM theory [41] is a powerful tool of modern quantum chemistry to analyze bond types via different key concepts such as electron density, $\rho(r)$, and Laplacian of the electron density, $\nabla^{2} \rho(r)$, which is the sum of the curvatures in the charge density along any orthogonal coordinate axes computed at the bond critical point (BCP) [47]. The $\lambda_{1}, \lambda_{2}$ and $\lambda_{3}$ are three eigenvalues of the Hessian matrix, which $\lambda_{1}, \lambda_{2}$ correspond to the perpendicular curvatures, while $\lambda_{3}$ provides a curvature along the internuclear axis. The $\lambda_{1} / \lambda_{3}$ ratio describes qualitatively the type of the corresponding chemical bonds [41, 48]. If, $\left|\lambda_{1} / \lambda_{3}\right|>1$, the charge density is concentrated, as the covalent bond. While, the electron density is largely concentrated in the atomic space for $\left|\lambda_{1} / \lambda_{3}\right|<1$, which corresponds to the interaction of closed shells (hydrogen, van der Waals, and ionic bonds). The sign of Laplacian of the electron density, $\nabla^{2} \rho(r)$, at the BCP indicates charge density is concentrated for $\nabla^{2} \rho(r)<0$ as the covalent bond, while $\nabla^{2} \rho(r)>0$ shows a depleted charge density, as in closed shell (electrostatic) interactions. Another topological parameter is the total energy density, $H(r)$,. It should be mentioned that H-bond is characterized by $\nabla^{2} \rho(r)<0, H(r)<0$ for strong H-bond, $\nabla^{2} \rho(r)>0, H(r)<0$ for medium H-bond, and $\nabla^{2} \rho(r)>0, H(r)>0$ for weak H-bond[41].

One of the important advantages of the AIM theory is the ability to estimate the energy of the intramolecular interactions based on the Espinosa correlation [49]:

$$
E_{H-B}=1 / 2 v(r)
$$


where $\mathrm{E}_{\mathrm{HB}}$ is the energy of interatomic interaction.

Table 2. The H-Bond (in $\AA$ ), curvature values of $\lambda_{1}, \lambda_{2}$, and $\lambda_{3},\left|\lambda_{1} / \lambda_{3}\right|$ ratio, electron density $\rho(r)$, Laplacian of the electron density $\nabla^{2} \rho(r)$, total energy density $H(r)$, and H-bond energy $\left(\mathrm{E}_{\mathrm{HB}}\right)$ for the selected rare sugars at the bond critical points at the B3LYP/6-31G* level of theory.

\begin{tabular}{|c|c|c|c|c|c|c|c|c|c|c|}
\hline Sugars & H-bonds & $\varepsilon$ & $\lambda_{1}$ & $\lambda_{2}$ & $\lambda_{3}$ & $\left|\lambda_{1} / \lambda_{3}\right|$ & $\rho(r)$ & $\nabla^{2} \rho(r)$ & $H(r)$ & $\begin{array}{c}E_{H B} \\
\left(\mathrm{kcal}^{\mathrm{mol}{ }^{-1}}\right)\end{array}$ \\
\hline Gulose & $\mathrm{O}_{6} \ldots \mathrm{HO}_{4}$ & 0.0778 & -0.0529 & -0.0491 & 0.2128 & 0.2485 & 0.0352 & 0.1108 & -0.0022 & 10.09 \\
\hline \multirow[t]{3}{*}{ Allose } & $\mathrm{O}_{3} \ldots \mathrm{HO}_{2}$ & 0.5477 & -0.0209 & -0.0135 & 0.1103 & 0.1891 & 0.0196 & 0.0823 & 0.0011 & 5.75 \\
\hline & $\mathrm{O}_{4} \ldots \mathrm{HO}_{6}$ & 0.0411 & -0.0339 & -0.0325 & 0.1520 & 0.2229 & 0.0254 & 0.0856 & -0.0008 & 7.22 \\
\hline & $\mathrm{O}_{1} \ldots \mathrm{HO}_{2}$ & 0.3826 & -0.0247 & -0.0178 & 0.1248 & 0.1976 & 0.0214 & 0.0823 & 0.0003 & 6.28 \\
\hline \multirow[t]{3}{*}{ Altrose } & $\mathrm{O}_{3} \ldots \mathrm{HO}_{4}$ & 1.1890 & -0.0191 & -0.0087 & 0.1007 & 0.1892 & 0.0181 & 0.0730 & 0.0007 & 5.29 \\
\hline & $\mathrm{O}_{4} \ldots \mathrm{HO}_{6}$ & 0.2004 & -0.0246 & -0.0205 & 0.1196 & 0.2058 & 0.0201 & 0.0745 & 0.0002 & 5.73 \\
\hline & $\mathrm{O}_{1} \ldots \mathrm{HO}_{2}$ & 0.6441 & -0.0229 & -0.0139 & 0.1170 & 0.1955 & 0.0204 & 0.0802 & 0.0005 & 5.99 \\
\hline \multirow[t]{2}{*}{ Talose } & $\mathrm{O}_{2} \ldots \mathrm{HO}_{4}$ & 0.0130 & -0.0618 & -0.0611 & 0.2560 & 0.2416 & 0.0402 & 0.1331 & -0.0021 & 11.73 \\
\hline & $\mathrm{O}_{4} \ldots \mathrm{HO}_{6}$ & 0.0747 & -0.0491 & -0.0457 & 0.2030 & 0.2420 & 0.0335 & 0.1082 & -0.0018 & 9.64 \\
\hline
\end{tabular}

Topological parameters and AIM molecular graphs for considered sugars are represented in Table 2 and Figure 2, respectively. Figure 2 illustrates one intramolecular $\mathrm{H}$-bond $\left(\mathrm{O}_{6} \ldots \mathrm{HO}_{4}\right)$ in gulose; two intramolecular $\mathrm{H}$-bonds $\left(\mathrm{O}_{3} \cdots \mathrm{HO}_{2}\right.$ and $\left.\mathrm{O}_{4} \cdots \mathrm{HO}_{6}\right)$ in allose, three intramolecular $\mathrm{H}$-bonds $\left(\mathrm{O}_{1} \cdots \mathrm{HO}_{2}\right.$, $\mathrm{O}_{3} \cdots \mathrm{HO}_{4}$, and $\left.\mathrm{O}_{4} \ldots \mathrm{HO}_{6}\right)$ in altrose, and three intramolecular $\mathrm{H}$-bonds $\left(\mathrm{O}_{1} \ldots \mathrm{HO}_{2}, \mathrm{O}_{2} \ldots \mathrm{HO}_{4}\right.$, and $\left.\mathrm{O}_{4} \ldots \mathrm{HO}_{6}\right)$ in talose. The acceptable range for the electron density and Laplacian of the electron density for H-bond formation are 0.002-0.035 and 0.024-0.139 a.u., respectively [50]. Table 2 shows the values of $\rho(r)$ and $\nabla^{2} \rho(r)$ at the BCP fall in the range of 0.0181-0.0402 (a.u.) and 0.0730-0.1331 (a.u.), respectively, implying the possibility of the formation of intramolecular H-bonds for these rare sugars. Based on the positive values of $\nabla^{2} \rho(r)$ and the ratio of $\left|\lambda_{1} / \lambda_{3}\right|<1$, the H-bonds are predominantly closed-shell electrostatic interactions. According to the values of $\nabla^{2} \rho(r)>0$ and $H(r)<0$, the $\mathrm{O}_{6} \ldots \mathrm{HO}_{4}$ bond in gulose, the $\mathrm{O}_{4} \ldots \mathrm{HO}_{6}$ bond in allose, and the $\mathrm{O}_{2} \ldots \mathrm{HO}_{4}$ and $\mathrm{O}_{4} \ldots \mathrm{HO}_{6}$ bonds in talose are considered as medium intramolecular $\mathrm{H}$-bonds. For the other H-bonds, with $\nabla^{2} \rho(r)>0, H(r)>0$, the weak intramolecular H-bonds were predicted.

Ellipticity, $(\varepsilon)$, is another interesting parameter which is defined as:

$$
\varepsilon=\left[\left(\lambda_{1} / \lambda_{2}\right)\right]-1
$$


Where as $\lambda_{1}$ and $\lambda_{2}$ are the curvatures of the density with respect to the two principal axes of $\mathrm{X}^{\prime}$ and $\mathrm{Y}^{\prime}$. Ellipticity is a measure of bond stability, i.e., a high ellipticity value indicates the instability of the bond [51].
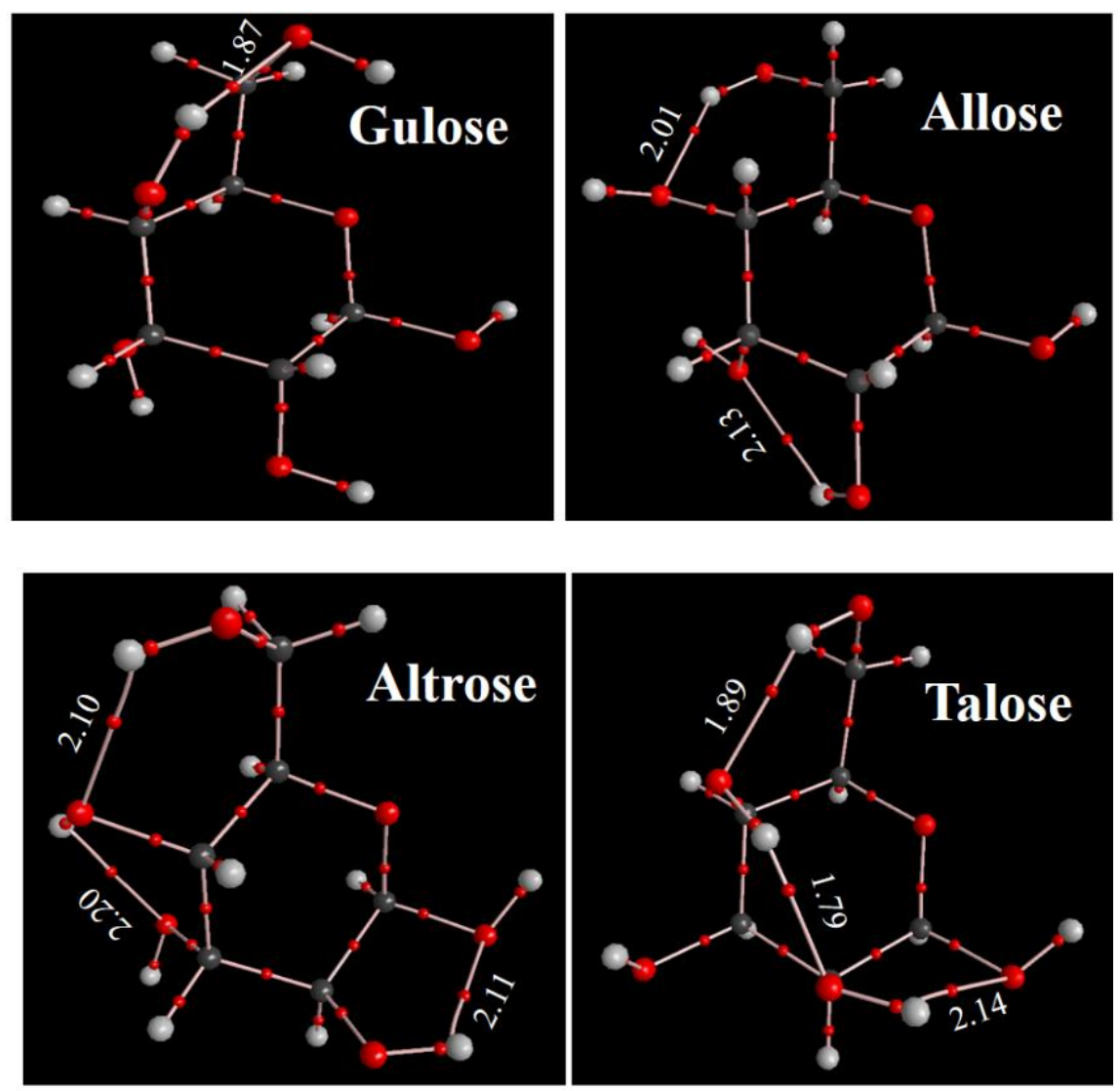

Figure.2 The optimized structure and AIM molecular graphs of gulose, allose, altrose, and talose sugars. Large circles correspond to attractors attributed to atomic positions: gray, hydrogen; black, carbon; and red, oxygen. Small circles are attributed to critical points: red, bond critical point (BCP).

It was found that the highest ellipticity value (1.1890 a.u.) was related to the $\mathrm{O}_{3} \ldots \mathrm{HO}_{4}$ bond in allose, while the lowest value $\left(0.0130\right.$ a.u.) was related to the $\mathrm{O}_{2} \ldots \mathrm{HO}_{4}$ bond in talose. As a result, the intramolecular $\mathrm{O}_{3} \ldots \mathrm{HO}_{4}$ bond in allose is less stable than the $\mathrm{O}_{2} \ldots \mathrm{HO}_{4}$ bond in talose. The largest $\mathrm{H}$-bond interaction energy value was observed for the $\mathrm{O}_{2} \ldots \mathrm{HO}_{4}$ bond in talose with the $\mathrm{E}_{\mathrm{HB}}=11.73\left(\mathrm{kcal}^{\mathrm{mol}}{ }^{-1}\right)$, which indicates the $\mathrm{O}_{2} \ldots \mathrm{HO}_{4}$ bond is the strongest intramolecular $\mathrm{H}$-bond in talose. After that, the $\mathrm{O}_{6} \ldots \mathrm{HO}_{4}$ bond in gulose $\left(\mathrm{E}_{\mathrm{HB}}=10.09 \mathrm{kcal} . \mathrm{mol}^{-1}\right)$ and $\mathrm{O}_{4} \ldots \mathrm{HO}_{6}$ bond in talose $\left(\mathrm{E}_{\mathrm{HB}}=9.64 \mathrm{kcal} \mathrm{mol}^{-1}\right)$ have the highest $\mathrm{H}$-bond interaction energy. The H-bond energies $\left(E_{H B}\right)$ for other bonds in these sugars are between 5.29-7.22 kcal.mol ${ }^{-1}$. The medium intramolecular $\mathrm{H}$-bonds in these sugars have the interaction energy $\mathrm{E}_{\mathrm{HB}} \geq 7$ $\left(\mathrm{kcal}_{\mathrm{mol}}{ }^{-1}\right)$. These values are in good agreement with our previous results for glucose and idose sugars $[25]$. 


\section{Natural Bond Orbital (NBO) analysis}

The NBO [32] analysis interpreted the electronic wave functions in terms of a set of occupied Lewis and a set of unoccupied non-Lewis localized orbitals. Delocalization effects can be identified from the presence of off-diagonal elements of the Fock matrix. The strengths of these delocalization interactions are estimated by the second-order perturbation theory $\left(E^{(2)}\right)$. Besides, the stabilization energy $\left(E^{(2)}\right)$ is associated with $i \rightarrow j$ delocalization, and is explicitly estimated by the following equation:

$$
E^{(2)}=\Delta E_{i j}=q_{i} \frac{F(i, j)^{2}}{\varepsilon_{j}-\varepsilon_{i}}
$$

Where $q_{i}$ is the $\mathrm{i}^{\text {th }}$ donor orbital occupancy, $\varepsilon_{i}$ and $\varepsilon_{j}$ are diagonal elements (orbital energies), and $\mathrm{F}(i, j)$ is the off-diagonal element. Therefore, there is a direct relationship between the off-diagonal elements and the orbitals overlap. The formation of H-bonds in the selected rare sugars implies that certain amounts of electronic charges are transferred from the lone pair of the oxygen atom to the anti-bonding orbital.

Table 3 shows some of the remarkable donor-acceptor interactions and their second order perturbation stabilization energies $\left(E^{(2)}\right)$ for studied rare sugars. As can be seen, the electron charge is transferred from the oxygen lone pair $\mathrm{LP}(\mathrm{O})$ in the donor fragment to the anti-bonding orbital, $\mathrm{BD}^{*}(\mathrm{O}-\mathrm{H})$, of an acceptor fragment $\left(\mathrm{n} \rightarrow \sigma^{*}\right)$. The larger the $E^{(2)}$ value indicates the more intensive interaction. The NBO results reveal three intramolecular $\mathrm{H}$-bonds, $\mathrm{O}_{2} \ldots \mathrm{HO}_{4}, \mathrm{O}_{4} \ldots \mathrm{HO}_{6}$, and $\mathrm{O}_{1} \ldots \mathrm{HO}_{2}$ for talose with the stabilization energies of $17.75,11.9$, and $2.1\left(\mathrm{kcal}^{\mathrm{mol}}{ }^{-1}\right)$, respectively. Whilst, there are three intramolecular H-bonds for altrose in $\mathrm{O}_{4} \ldots \mathrm{HO}_{6}, \mathrm{O}_{3} \ldots \mathrm{HO}_{4}$, and $\mathrm{O}_{1} \ldots \mathrm{HO}_{2}$, bonds with stabilization energies of 2.90, 2.58, and 2.34 $\left(\mathrm{kcal}^{\mathrm{mol}}{ }^{-1}\right)$, respectively. The highest stabilization energy and strongest $\mathrm{H}$-bond were identified for $\mathrm{O}_{4} \ldots \mathrm{HO}_{6}$ bond in talose since it has the highest $\mathrm{H}$-bond energy, the smallest bond length, and the highest bond angle. As a result, altrose with three low H-bonds energies and low ellipticities is less stable than talose. The highest stabilization energy, the smallest bond length, and the highest bond angle were identified for O4...HO6 bond in talose. In summary, the stabilization energies values clearly indicate the charge transfer takes place between the donor and acceptor atoms. Accordingly, the favorable intramolecular Hbonds will construct in four investigated rare sugars. 
Table 3. The second-order perturbation energies $E^{(2)}\left(\mathrm{kcal}_{\mathrm{mol}} \mathrm{m}^{-1}\right)$ corresponds to the most important charge transfer (donor $\rightarrow$ acceptor), $\varepsilon_{i}$ and $\varepsilon_{j}$ are diagonal elements (orbital energies), and $\mathrm{F}(i, j)$ is the off-diagonal element in the selected rare at the B3LYP/6-31G* level of theory.

\begin{tabular}{lccccc}
\hline Rare sugars & $\begin{array}{c}\text { Donor } \mathrm{NBO}_{(i)} \\
n(\mathrm{O})\end{array}$ & $\begin{array}{c}\mathrm{Acceptor} \mathrm{NBO}_{(j)} \\
\delta^{*}(\mathrm{O}-\mathrm{H})\end{array}$ & $\begin{array}{c}E^{(2)} \mathrm{kcal} \cdot \mathrm{mol}^{-1} \\
n(\mathrm{O}) \rightarrow \sigma^{*}(\mathrm{O}-\mathrm{H})\end{array}$ & $\begin{array}{c}\varepsilon_{j}-\varepsilon_{i} \\
\text { a.u. }\end{array}$ & $\begin{array}{c}\mathrm{F}(\mathrm{i}, \mathrm{j}) \\
\text { a.u. }\end{array}$ \\
\hline Gulose & $\mathrm{LP}_{(2)} \mathrm{O}_{6}$ & $\mathrm{BD}^{*} \mathrm{HO}_{4}-\mathrm{O}_{4}$ & 13.61 & 0.76 & 0.09 \\
& $\mathrm{LP}_{(1)} \mathrm{O}_{3}$ & $\mathrm{BD}^{*} \mathrm{HO}_{2}-\mathrm{O}_{2}$ & 2.14 & 1.00 & 0.04 \\
Altrose & $\mathrm{LP}_{(2)} \mathrm{O}_{4}$ & $\mathrm{BD}^{*} \mathrm{HO}_{6}-\mathrm{O}_{6}$ & 6.48 & 0.81 & 0.06 \\
& $\mathrm{LP}_{(1)} \mathrm{O}_{1}$ & $\mathrm{BD}^{*} \mathrm{HO}_{2}-\mathrm{O}_{2}$ & 2.34 & 1.02 & 0.04 \\
& $\mathrm{LP}_{(2)} \mathrm{O}_{3}$ & $\mathrm{BD}^{*} \mathrm{HO}_{4}-\mathrm{O}_{4}$ & 2.58 & 0.76 & 0.04 \\
& $\mathrm{LP}_{(2)} \mathrm{O}_{4}$ & $\mathrm{BD}^{*} \mathrm{HO}_{6}-\mathrm{O}_{6}$ & 2.90 & 0.76 & 0.04 \\
& $\mathrm{LP}_{(1)} \mathrm{O}_{1}$ & $\mathrm{BD}^{*} \mathrm{HO}_{2}-\mathrm{O}_{2}$ & 2.11 & 1.01 & 0.04 \\
& $\mathrm{LP}_{(2)} \mathrm{O}_{2}$ & $\mathrm{BD}^{*} \mathrm{HO}_{4}-\mathrm{O}_{4}$ & 17.75 & 0.84 & 0.11 \\
& $\mathrm{LP}_{(2)} \mathrm{O}_{4}$ & $\mathrm{BD}^{*} \mathrm{HO}_{6}-\mathrm{O}_{6}$ & 11.92 & 0.78 & 0.09 \\
\hline
\end{tabular}

\section{Infrared spectroscopy}

The structural and analytical properties of carbohydrates are difficult to investigate since the physical and chemical properties of the basic units in these polymeric systems are very similar. Infrared spectroscopy is a powerful tool to monitor the presence and nature of the $\mathrm{H}$-bonds; inter- or intra-molecular $\mathrm{H}$-bond [52]. The existence of the H-bond leads to significant changes in infrared spectroscopy which resulted in the stiffness bond and altered the frequency of $\mathrm{O}-\mathrm{H}$ stretching and produces broadband that occurs in the 3700$3600 \mathrm{~cm}-1$ range [53]. The probability of the formation of intramolecular (internal) H-bond increased If the hydroxy group bands do not change dramatically with concentration [54]. The $\mathrm{OH}$ group vibrations are very sensitive to the environment, therefore, there are pronounced shifts in the spectra of the $\mathrm{H}$-bond towards the low frequency and red-shift occurs. As such, the H-bonded OH stretching (H-O...H) shifts toward 3500 to $2500 \mathrm{~cm}^{-1}$ [53]. The formed intramolecular $\mathrm{H}$-bonds cause their vibrational modes to be vibrated at a lower frequency than the normal vibration frequency in all known molecular systems including; amines, $\mathrm{O}-\mathrm{H}$ groups, and halogen $-\mathrm{H}$ interactions $[55,56]$. The lowering of the frequency appears to be a function of the degree and strength of the H-bond [57]. However, it is not well established experimental IR spectroscopy to determine intra-molecular H-bond. In this study, we used the theoretical IR spectroscopy method at the B3LYP/6-31G* level to study the presence of H-bond in the selected rare sugars. We have used the scaling factor value of 0.9614 [58] for the B3LYP/6-31G* method since the DFT method systematically overestimates the vibrational wavenumbers [59]. We carried out the scaling factor only for allose and talose because we had not found any experimental FT-IR results for gulose and altrose.

The calculated and scaled $\mathrm{OH}$-stretching vibrations in $\mathrm{H}$-bonded and intramolecular $\mathrm{H}$-bond frequencies of four rare sugars are listed in Table 4 and the corresponded IR spectrum is presented in Figure 3. According to Table 4, the calculated frequencies of $\mathrm{O}-\mathrm{H}$ stretching for free hydroxyl groups are in the region of 3670$3600 \mathrm{~cm}^{-1}$ for four rare sugars. It was found that the vibration frequency of the $\mathrm{HO}_{6}$ group in gulose was 
shifted to $3465 \mathrm{~cm}^{-1}$, whilst the calculated vibration frequencies of the $\mathrm{HO}_{2}$ and $\mathrm{HO}_{6}$ groups in allose were shifted to 3585 , and $3565 \mathrm{~cm}_{-1}$, respectively (see Figure 3). On the other hand, the lowest frequency was associated with the $\mathrm{HO}_{2}, \mathrm{HO}_{4}$, and $\mathrm{HO}_{6}$ groups at 3590, 3591, and $3568 \mathrm{~cm}^{-1}$ for altrose. However, the calculated frequencies of $\mathrm{HO}_{2}, \mathrm{HO}_{4}$ and $\mathrm{HO}_{6}$ groups at 3593, 3360, and $3495 \mathrm{~cm}^{-1}$ for talose (see in Figure 3) revealed these hydroxyl groups are capable of forming the intramolecular $\mathrm{H}-$ bonds. Accordingly, the intramolecular H-bonds strength was reflected in lowering of the $\mathrm{O}-\mathrm{H} . . . \mathrm{O}$ stretching frequencies in selected rare sugars which exhibited the red-shift.

Table 4. The observed (Exp.), calculated and scaled O-H stretching frequencies (in $\mathrm{cm}^{-1}$ ) for the selected rare sugars at B3LYP/6-31G* level of theory. The intramolecular H-bond stretching frequencies are bold.

\begin{tabular}{llccccc}
\hline Rare sugars & FT-IR & $\mathrm{HO}_{1}$ & $\mathrm{HO}_{2}$ & $\mathrm{HO}_{3}$ & $\mathrm{HO}_{4}$ & $\mathrm{HO}_{6}$ \\
\hline Gulose & Calculated & 3650 & 3655 & 3619 & $\mathbf{3 4 6 5}$ & 3602 \\
& Scaled & 3509 & 3514 & 3479 & $\mathbf{3 3 3 1}$ & 3463 \\
Allose & Calculated & 3644 & $\mathbf{3 5 8 5}$ & 3625 & 3643 & $\mathbf{3 5 6 5}$ \\
& Scaled & 3503 & $\mathbf{3 4 4 7}$ & 3485 & 3502 & $\mathbf{3 4 2 7}$ \\
& a'Exp. & 3492 & - & 3390 & 3340 & 3139 \\
Altrose & Calculated & 3653 & $\mathbf{3 5 9 0}$ & 3669 & $\mathbf{3 5 9 1}$ & $\mathbf{3 5 6 8}$ \\
& Scaled & 3512 & 3451 & 3527 & 3452 & 3430 \\
Talose & Calculated & 3648 & $\mathbf{3 5 9 3}$ & 3619 & $\mathbf{3 3 6 0}$ & $\mathbf{3 4 9 5}$ \\
& Scaled & 3507 & 3454 & 3479 & 3230 & 3360 \\
& aExp. & 3400 & 3295 & 3370 & - & - \\
\hline
\end{tabular}

${ }^{\mathrm{a}}$ The experimental FT-IR values reported for $\beta$-D-allose and $\alpha$-talose [60].

Furthermore, gulose, altrose, and talose have two $(\mathrm{OH})$ groups in the axial orientation, whilst allose has two $(\mathrm{OH})$ groups in the equatorial orientation, therefore, slight differences have been found between their $\mathrm{OH}$ stretching frequencies. It seems that the hydroxyl groups in axial orientation are shown the lowest stretching frequency due to the formation of intramolecular H-bond. As an example, the values of $3593 \mathrm{~cm}^{-}$ ${ }^{1}$ and $3360 \mathrm{~cm}^{-1}$ are assigned to the $\mathrm{HO}_{2}$ and $\mathrm{HO}_{4}$ groups in the axial orientation for talose, respectively (see Figure 1). Therefore, according to the orientation of the $\mathrm{OH}$ groups (axial/equatorial) on the $\mathrm{C}$ atoms, these rare sugars could have different H-bonds with different strengths and energies. Our scaled vibrational frequency results are in good agreement with the experimental values [60] and other calculated frequencies by B3LYP and HF methods and various basis sets [59] and also other available literatures [61-63]. As can be seen from IR spectra in Figure 3, the $(\mathrm{OH})$ vibration frequency for selected rare sugars confirmed the existence of two types of H-bonds, one is related to the free hydroxyl groups and the other one belongs to the intramolecular H-bonds.

It is clear that the $\mathrm{O}_{2} \ldots \mathrm{HO}_{4}-\mathrm{O}_{4}$ bond in talose with the energy of $\mathrm{E}_{\mathrm{HB}}=11.73 \mathrm{kcal} \mathrm{mol}^{-1}$ has the lowest frequency of $3360 \mathrm{~cm}^{-1}$ (see Table 2,4) which is comparable with the previous resul of Desiraju et al [55] and is in excellent agreement with our previous study for glucose and idose sugars [25]. The change of the $\mathrm{X}-\mathrm{H}$ bond length is related to the charge transfer. In the case of the red-shift, the small amount of charge 
is transferred from the lone pair of the $\mathrm{O}$ atom to the anti-bonding $\mathrm{H}-\mathrm{O}$ orbital of the molecule. The scaled frequencies for the $\mathrm{OH}$ stretching vibrations of allose are extended in the $3503-3427 \mathrm{~cm}^{-1}$ region, whilst the observed (experimental FT-IR) values are at 3491-3139 $\mathrm{cm}^{-1}$ [60]. Besides, the scaled frequencies for the $\mathrm{OH}$ stretching vibrations of talose are extended in the $3507-3230 \mathrm{~cm}^{-1}$, while the observed (experimental FT-IR) values are at 3400-3295 $\mathrm{cm}^{-1}$. Table 4 compares the scaled and observed (experimental) O-H stretching vibration frequencies of $\beta$-talose with $\alpha$-talose, and allose. On the other hand, there is a good agreement between our calculated and scaled results with the observed frequencies of $\beta$-D-allose and $\alpha$-Dtalose in the crystalline state [60]. Actually, from the IR results of the Gaussian calculation, we can distinguish the IR values of each $\mathrm{OH}$ group seperately in the Gauss view. In fact, the most stable H-bond interaction causes the highest perturbation energy $\left(E^{(2)}\right)$ and lowest IR frequency. Therefore, this could be a reference to distinguish the different H-bond (i.e; the lowest IR frequency $\left(3360 \mathrm{~cm}^{-1}\right)$ is related to the strongest intramolecular H-bonds $\left(\mathrm{O}_{2} \rightarrow \mathrm{HO}_{4}-\mathrm{O}_{4}\right)$ due to its $E^{(2)}=17.75 \mathrm{kcal} . \mathrm{mol}^{-1}$ and $\mathrm{E}_{\mathrm{HB}}=11.73 \mathrm{kcal} . \mathrm{mol}^{-}$ ${ }^{1)}$.
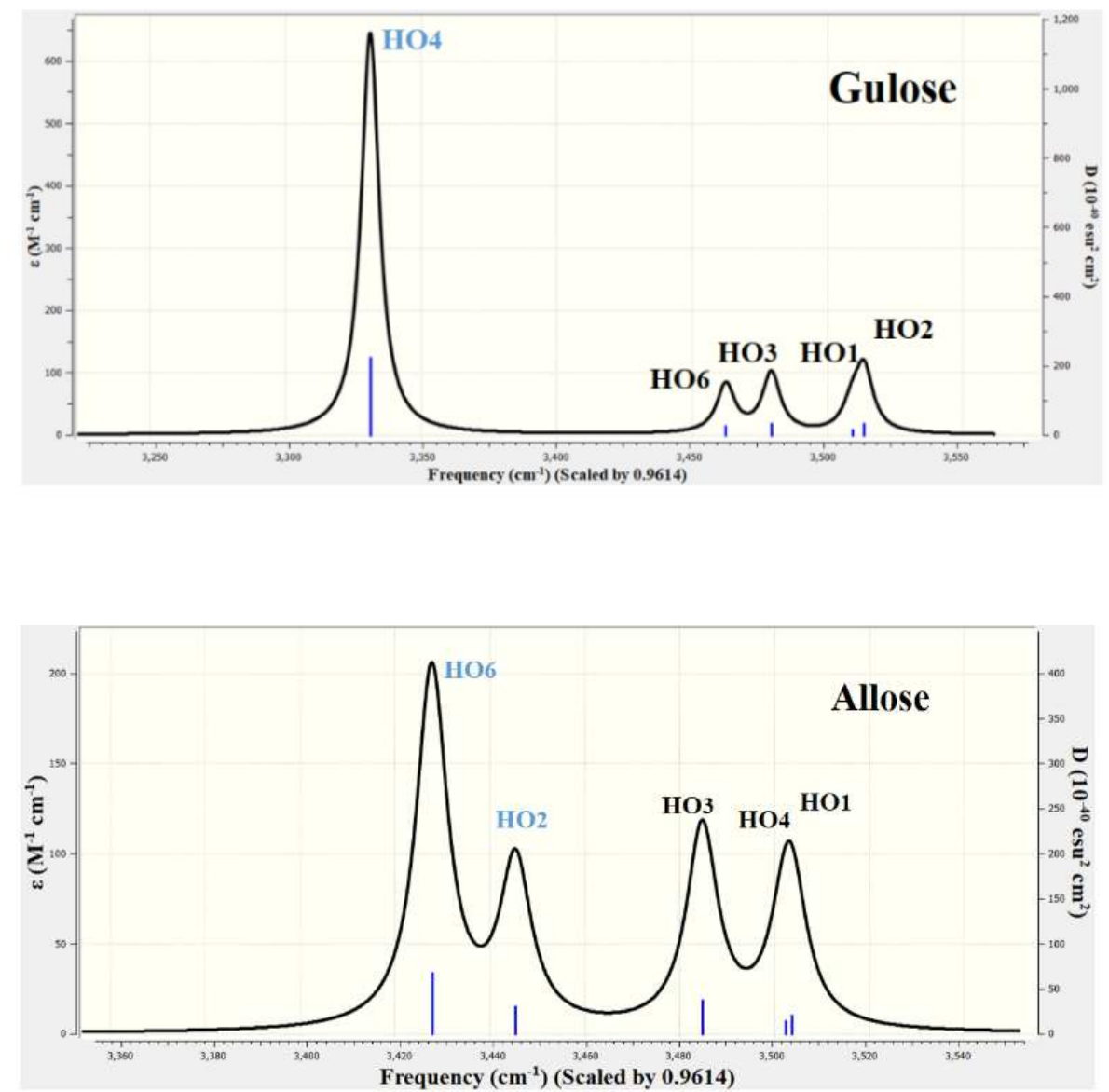

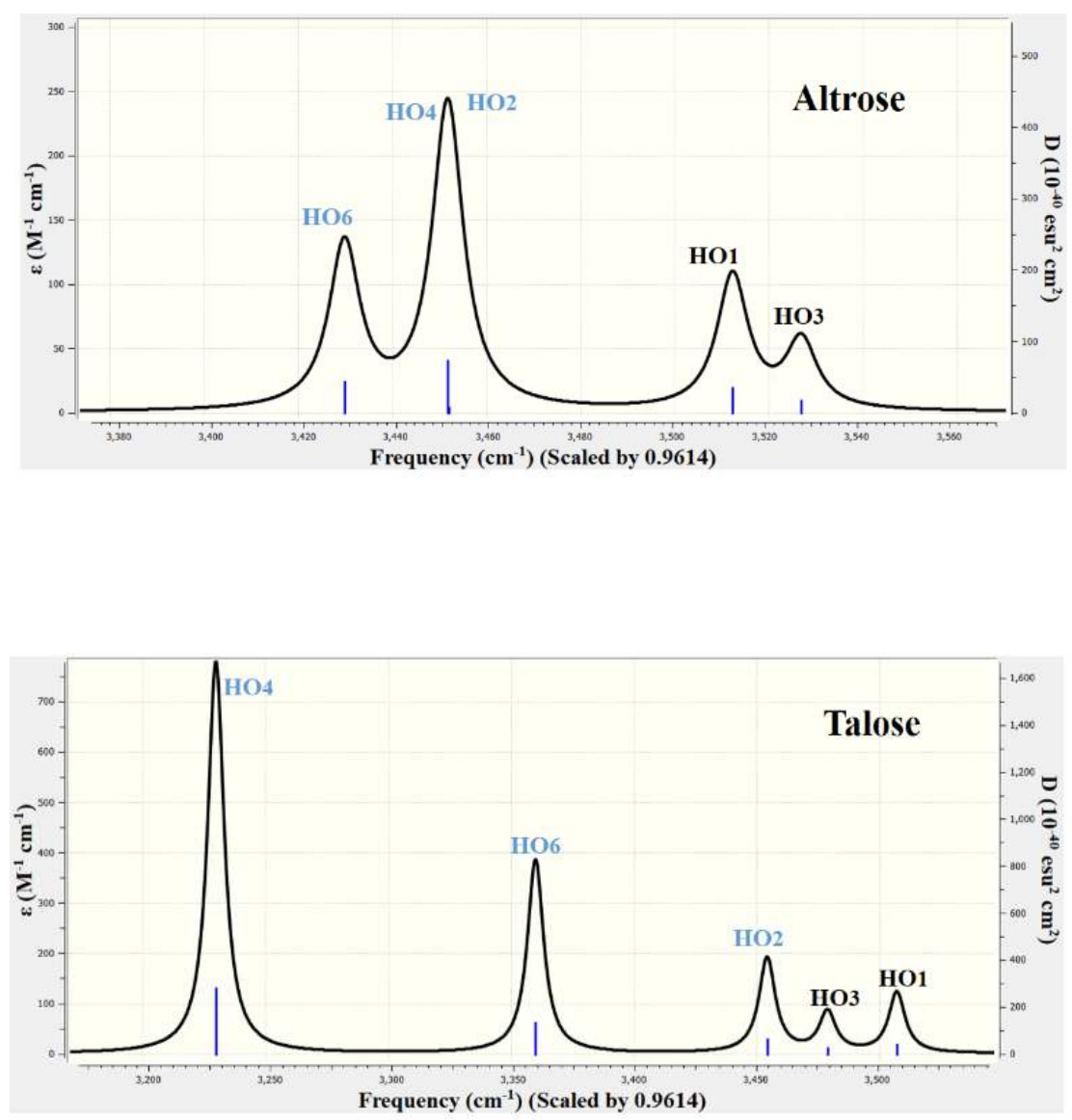

Figure.3 Theoretical FT-IR spectra by B3LYP/6-31G* method for gulose, allose, altrose, and talose. Free hydroxyl groups illustrated with black color whereas blue colors are intramolecular H-bonds that were shifted to low frequencies.

\section{Conclusions}

Three methods, namely DFT, AIM, and NBO were used to investigate the existence, nature, and strength of the $\mathrm{H}$-bonds formed in the four rare sugars including; gulose, allose, altrose, and talose. It was found that the H-bond lengths for selected rare sugars are between 1.79 to $2.20(\AA)$, and bond angles are in the range of $113^{\circ}-144^{\circ}$. A number of different H-bonds were identified for each sugar by AIM analysis. The value of $\rho(r)$ and $\nabla^{2} \rho(r)$ at BCP fall in the range of 0.0181-0.0402 (a.u.) and 0.0730-0.1331 (a.u.), respectively, implying the possibility of the formation of intramolecular H-bonds in these rare sugars. The formed intramolecular H-bonds were mostly closed-shell interactions based on the positive values of $\nabla^{2} \rho(r)$ and also the ratio of $\left|\lambda_{1} / \lambda_{3}\right|<1$. The intramolecular H-bonds at $\mathrm{O}_{3} \ldots \mathrm{HO}_{2}$ bond in allose, the $\mathrm{O}_{1} \ldots \mathrm{HO}_{2}$ in talose and three intramolecular H-bonds in altrose are not stable based on their ellipticity values. According to the $\mathrm{H}$-bond length and stabilization energies, the $\mathrm{O}_{2} \ldots \mathrm{HO}_{4}$ bond in talose (the bond length $=1.79(\AA)$ and bond angle $=143^{\circ}$ ), and the $\mathrm{O}_{6 . .} . \mathrm{HO}_{4}$ bond in gulose (the bond length $=1.87(\AA)$ and bond angle $=144^{\circ}$ ) are the most stable intramolecular H-bonds in these sugars. The H-bond strength in gulose is higher than that in 
allose, altrose, and talose due to the existence of the $\mathrm{OH}$ group on $\mathrm{C} 6$, making gulose sugar more stable than the other rare sugars. The existing $\mathrm{OH}$ groups in axial/equatorial in these rare sugars make them stabilize through intramolecular H-bonds. Furthermore, the NBO analysis confirmed that a certain amount of electronic charge is transferred from the lone pair of oxygen to the empty anti-bonding orbital (H-O) group. It is clear that the delocalization of energy in $\mathrm{O}_{2} \ldots \mathrm{HO}_{4}$ and $\mathrm{O}_{4} \ldots \mathrm{HO}_{6}$ bonds in talose and $\mathrm{O}_{6} \ldots \mathrm{HO}_{4}$ bond in gulose are higher than the other H-bonds in the studied sugars, indicating these bonds are the strongest intramolecular $\mathrm{H}$-bonds. The calculated frequencies of $\mathrm{O}-\mathrm{H}$ stretching of intramolecular $\mathrm{H}$-bond for $\mathrm{O}_{6} \ldots \mathrm{HO}_{4}$ bond in gulose; $\mathrm{O}_{3} \ldots \mathrm{HO}_{2}$ and $\mathrm{O}_{4} \ldots \mathrm{HO}_{6}$ bonds in allose; $\mathrm{O}_{1} \ldots \mathrm{HO}_{2}, \mathrm{O}_{3} \ldots \mathrm{HO}_{4}$, and $\mathrm{O}_{4} \ldots \mathrm{HO}_{6}$ bonds in altrose; and $\mathrm{O}_{1} \ldots \mathrm{HO}_{2}, \mathrm{O}_{2} \ldots \mathrm{HO}_{4}$ and $\mathrm{O}_{4} \ldots \mathrm{HO}_{6}$ bonds in talose shifted to less than the $\mathrm{O}-\mathrm{H}$ stretching of free hydroxyl groups, implying the intramolecular H-bonds appear in low frequencies which caused the red-shift. In summary, the H-bonds formation and their strengths in these rare sugars are In summary, the stabilization energies affected by the hydroxyl group orientations (axial or equatorial). The lowest IR frequency in each sugar is related to the highest stabilization energy and the most strongest intramolecular H-bonds. Although rare sugars have significant uses, their small amounts in Nature make it difficult to conduct experimental studies. Therefore, their theoretical studies can help us to identify and have a deep understanding of them.

\section{Declarations;}

Funding: The authors did not receive support from any organization for the submitted work.

Conflicts of interest/Competing interests: The authors declare that they have no known competing financial interests or personal relationships that could have appeared to influence the work reported in this paper.

Availability of data and material: The datasets generated during and/or analysed during the current study are available from the corresponding author on reasonable request.

Code availability: Spartan $14-$ Gaussian 09

Authors' contribution: All authors contributed to the study conception and design. Material preparation, data collection and analysis were performed by [Zahrabatoul Mosapour Ktena], [Mozhan Razi] [Sara Ahmadi]. The first draft of the manuscript was written by [Zahrabatoul Mosapur Kotena] and all authors commented on previous versions of the manuscript. All authors read and approved the final manuscript. 


\section{References}

1. $\mathrm{Mu} \mathrm{W}$, et al., Recent advances on applications and biotechnological production of D-psicose. . Appl Microbiol Biotechnol, 2012. 94: p. 1461-1467.

2. Hoshikawa H, et al., Enhancement of the radiation effects by D-allose in head and neck cancer cells. Cancer Lett, 2011. 306: p. 60-66.

3. Granström TB, Izumori K, and L. M, A rare sugar xylitol. Part II: biotechnological production and future applications of xylitol. Appl Microbiol Appl Microbiol Biotechnol 74: p. 273-276.

4. $\quad$ Levin GV, et al., Sugar substitutes: their energy values, bulk characteristics, and potential health benefits. Am J Clin Nutr 1995. 62: p. 1161S-1168S.

5. Tang, S.-Y., Rare Sugars: Applications and Enzymatic Production. J Biocatal Biotransform, 2012. 01.

6. $\quad$ https://www.alliedmarketresearch.com/rare-sugars-market.

7. $\quad$ Robyt, J., Essentials of carbohydrate chemistry. 1998: Springer, Berlin.

8. $\quad$ Kajikawa, T., et al., Reactivity of rare sugar D-allose during glycation of human serum albumin. J Anal BioSci, 2010. 33(3).

9. Kano, A., et al., The rare sugar d-allose acts as a triggering molecule of rice defence via ROS generation. $\mathrm{J}$ Exp Bot, 2013. 64(16): p. 4939-4951.

10. Kennedy, J. and C. White, Carbohydrates Edited by PM Collins, Chapman and Hall. Brit Polym J, 1989. 21(3): p. 278-279.

11. Lim YR and O. DK, Microbial metabolism and biotechnological production of D-allose. Appl Microbiol Biotechnol, 2011. 91: p. 229-235.

12. Stack, R.J., Microbial production of L-altrose. 1990, Google Patents.

13. Swain, M., et al., Identification of $\beta$-l-gulose as the sugar moiety of the main polar lipid of Thermoplasma acidophilum. Biochimica et Biophysica Acta (BBA)-Lipids and Lipid Metabolism, 1997. 1345(1): p. 56-64.

14. Sazalee, S.A., N. Ahmad, and R. Hashim, Investigation of self-assembly properties and the effect of tween series co-surfactants on the stability of nonionic branched-chain glycolipid hexosomes. Colloid Surface A, 2017. 529: p. 210-221.

15. Panico, R., W. Powell, and J. Richer, A guide to IUPAC nomenclature of organic compounds: recommendations 1993. International Union of Pure Applied Chemistry. Commission on the Nomenclature of Organic Chemistry. 1993, Blackwell Scientific, Oxford.

16. G.A Jeffrey and W.Saenger, Hydrogen Bonding in Biological Structures. 1994, Heidelberg: Springer-Verlag.

17. $\quad$ Emsley, J., Very strong hydrogen bonding. Chem. Soc. Rev., 1980. 9(1): p. 91-124.

18. Claesson, P.M., et al., Short-range interactions between non-ionic surfactant layers. Phys Chem Chem Phys, 2006. 8(47): p. 5501-5514.

19. Larson, J. and T. McMahon, Gas-phase bihalide and pseudobihalide ions. An ion cyclotron resonance determination of hydrogen bond energies in $X H Y$-species $(X, Y=F, C l, B r, C N)$. Inorg Chem, 1984. 23(14): p. 2029-2033.

20. Lomas, J.S., Intramolecular $\mathrm{O}-\mathrm{H} \cdots \mathrm{O}$ and $\mathrm{C}-\mathrm{H} \cdots \mathrm{O}$ hydrogen bond cooperativity in $\mathrm{D}$-glucopyranose and D-galactopyranose - A DFT/GIAO, QTAIM/IQA, and NCI approach. Mag Reson Chem, 2018. 56(8): p. 748766.

21. Hermansson, M. and G. von Heijne, Inter-helical hydrogen bond formation during membrane protein integration into the ER membrane. J Mol Bio, 2003. 334(4): p. 803-809.

22. Arneson, L.S., et al., Hydrogen bond integrity between MHC class II molecules and bound peptide determines the intracellular fate of MHC class II molecules. J Immunol, 2001. 167(12): p. 6939-6946.

23. Lipinski, C.A., et al., Experimental and computational approaches to estimate solubility and permeability in drug discovery and development settings IPII of original article: S0169-409X(96)00423-1. The article was originally published in Adv Drug Deliver Rev 23 (1997) 3-25.1. Ad Drug Deliver Rev, 2001. 46(1): p. 3-26.

24. Mosapour Kotena, Z., R. Behjatmanesh-Ardakani, and R. Hashim, AIM and NBO analyses on hydrogen bonds formation in sugar-based surfactants ( $\alpha / \beta$-d-mannose and n-octyl- $\alpha / \beta$ - $d$-mannopyranoside): $a$ density functional theory study. Liq Cryst, 2014. 41(6): p. 784-792.

25. Kotena, Z.M. and S.B. Mohamad, Bifurcated hydrogen bond in rare sugar by computational study. Mol Cryst Liq Cryst, 2017. 646(1): p. 31-40.

26. Kotena, Z.M. and A. Fattahi, Influence of H-bonds on acidity of deoxy-hexose sugars. J Phys Org Chem, 2020. 33(10).

27. Kotena, Z.M. and A. Fattahi, Comparison of acidity and metal ion affinity of D-Glucosamine and N-acetylD-glucosamine, a DFT study. J Mol Graph Model, 2020. 98: p. 107612.

28. Lomas, J.S. and L. Joubert, On the importance of intramolecular hydrogen bond cooperativity in d-glucose - an NMR and QTAIM approach. Mag Reson Chem, 2017. 55(10): p. 893-901.

29. Bader, R.F., A quantum theory of molecular structure and its applications. Chem Rev, 1991. 91(5): p. 893928.

30. Espinosa, E., et al., Topological analysis of the electron density in hydrogen bonds. Acta Crystalloger B, 1999. 55(4): p. 563-572.

31. Weinhold, F., Nature of H-bonding in clusters, liquids, and enzymes: an ab initio, natural bond orbital perspective. J Mol Struct, 1997. 398: p. 181-197.

32. Reed, A.E., L.A. Curtiss, and F. Weinhold, Intermolecular interactions from a natural bond orbital, donoracceptor viewpoint. Chem Rev, 1988. 88(6): p. 899-926. 
33. Spartan '14', Wavefunction, Inc., Irvine, CA,. 2014. V1.1.4.

34. Becke, A.D., Density-functional thermochemistry. III. The role of exact exchange. J. Chem. Phys, 1993. 98(7): p. 5648-5652.

35. M. J. Frisch, G.W.T., H. B. Schlegel, et al, Gaussian 09 ,Revision A. 02. 2009: Wallingford CT

36. Appell, M., J.L. Willett, and F.A. Momany, DFT study of $\alpha$ - and $\beta$-d-mannopyranose at the B3LYP/6$311++G^{* *}$ level. Carbohyd Res, 2005. 340(3): p. 459-468.

37. S., C.C., et al., On the Path to Glycan Conformer Identification: Gas-Phase Study of the Anomers of Methyl Glycosides of N-Acetyl-d-Glucosamine and N-Acetyl-d-Galactosamine. Int. J. Mass Spectrom, 2012. 330332: p. 285-294.

38. Momany, F.A., et al., B3LYP/6-311++G** geometry-optimization study of pentahydrates of $\alpha$ - and $\beta$ - $d$ glucopyranose. Carbohyd Res, 2005. 340(9): p. 1638-1655.

39. Momany, F.A., et al., DFT study of $\alpha$ - and $\beta$-d-galactopyranose at the B3LYP/6-311++G** level of theory. Carbohyd Res, 2006. 341(4): p. 525-537.

40. Popelier, P.L. and P. Hall, Atoms in molecules: an introduction. 2000, New Jersy: Prentice Hall

41. Bader, R., Atoms in molecules. A quantum theory. 1995, Oxford: Oxford University Press.

42. Biegler-König F, et al., AIM2000,. 2002, University of Applied Sciences: Bielefeld.

43. Glendening, E., et al., NBO 3.1. 2003.

44. Jeffrey G. A. and Saenger . W, Hydrogen Bonding in Biology and Chemistry 1991, Berlin: Springer-Verlag

45. Mosapour Kotena, Z., et al., Hydrogen bonds in galactopyranoside and glycopyranoside: a density functional theory. J Mol Model, 2013. 19(2): p. 589-599.

46. Kotena, Z.M. and A. Fattahi, Comparison of acidity and metal ion affinity of D-Glucosamine and N-acetylD-glucosamine, a DFT study. J Mol Graph Model, 2020. 98: p. 107612.

47. Popelier, P., Characterization of a dihydrogen bond on the basis of the electron density. J Phys Chem A, 1998. 102(10): p. 1873-1878.

48. Bader, R.F.W. and H. Essén, The characterization of atomic interactions. J Chem Phys, 1984. 80(5): p. 19431960.

49. Espinosa, E., E. Molins, and C. Lecomte, Hydrogen bond strengths revealed by topological analyses of experimentally observed electron densities. Chem Phys Lett, 1998. 285(3-4): p. 170-173.

50. Popelier, P. and R. Bader, The existence of an intramolecular $C-H .$. O hydrogen bond in creatine and carbamoyl sarcosine. Chem Phys Lett, 1992. 189(6): p. 542-548.

51. $\quad$ Bader, R.F.W., A quantum theory of molecular structure and its applications. Chem Rev, 1991. 91(5): p. 893-928.

52. Smith, A.L., Applied infrared spectroscopy: fundamentals, techniques, and analytical problem-so lving. 1979, New York: Wiley.

53. B. Stuart, Infrared Spectroscopy: Fundamentals and Applications. 2004, NeSpartan '14',Wavefunctionw Jercy: John Wiley \& Sons.

54. Coates, J., Interpretation of Infrared Spectra, A Practical Approach, in Encyclopedia of Analytical Chemistry, R.A. Meyers, Editor. 2000, John Wiley \& Sons Ltd: Chichester. p. 10815-10837.

55. Saha, S., et al., IR spectroscopy as a probe for $C-H \cdots X$ hydrogen bonded supramolecular synthons. CrystEngComm, 2015. 17(6): p. 1273-1290.

56. Stuart, B., Infrared Spectroscopy. 2005, New Jersey: John Wiley \& Sons, Inc.

57. Coates, J., Interpretation of Infrared Spectra, A Practical Approach-Infrared Spectroscopy. 2006, Wiley \& Sons, Ltd: Wiely online library.

58. Scott, A.P. and L. Radom, Harmonic Vibrational Frequencies: An Evaluation of Hartree-Fock, Møller-Plesset, Quadratic Configuration Interaction, Density Functional Theory, and Semiempirical Scale Factors. J Phys Chem, 1996. 100(41): p. 16502-16513.

59. Ye, Y., et al., Experimental and density functional theory and ab initio Hartree-Fock study on the vibrational spectra of 2-(4-fluorobenzylideneamino)-3-mercaptopropanoic acid. Spectrochim Acta Part A, 2007. 68(1): p. $85-93$.

60. C Reguieg, N Yousfi, and M. Sekkal-Rahal, Normal coordinates analyses of beta-D-allose and alpha-Dtalose in the crystalline state. Spectrochim Acta A Mol Biomol Spectrosc, 2007. 67(3-4): p. 966-75.

61. Sundaraganesan, N., et al., FT-IR, FT-Raman spectra and ab initio HF, DFT vibrational analysis of $p$ chlorobenzoic acid. Spectrochim Acta Part A, 2008. 69(3): p. 871-879.

62. Ś Swisłocka, R., J. Piekut, and W. Lewandowski, The relationship between molecular structure and biological activity of alkali metal salts of vanillic acid: Spectroscopic, theoretical and microbiological studies. Spectrochim Acta Part A, 2013. 100: p. 31-40.

63. Sundaraganesan, N., et al., FT-Raman and FT-IR spectra, ab initio and density functional studies of 3,4dichlorobenzyl alcohol. Spectrochim Acta Part A, 2006. 65(3): p. 826-832. 
Figures

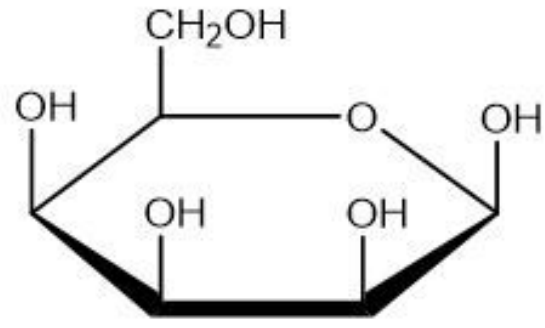

$\beta$-Talose

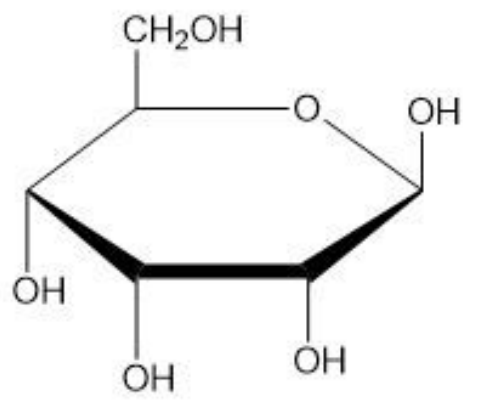

$\beta$-Allose

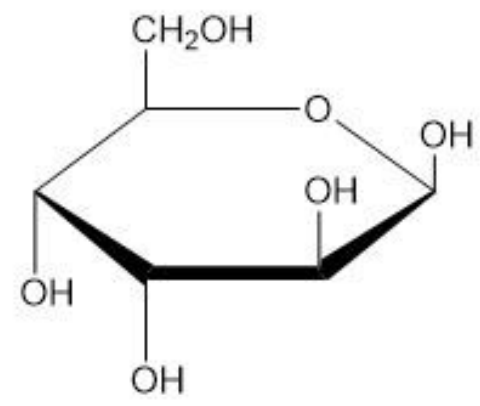

$\beta$-Altrose

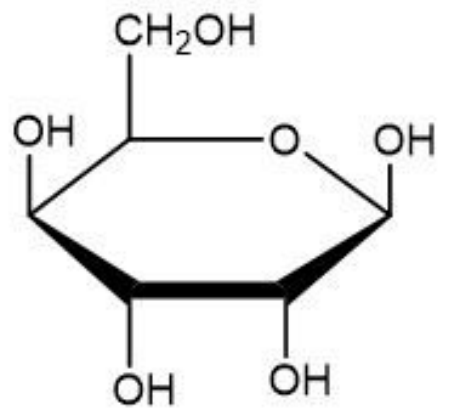

$\beta$-Gulose

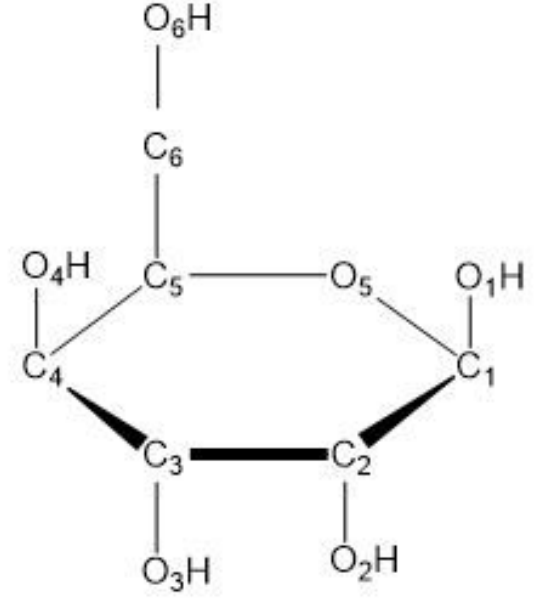

${ }^{a} \beta$-Gulose

\section{Figure 1}

Schematic view of molecular structures of gulose, allose, altrose, and talose sugars. aThe IUPAC naming convention for carbohydrates has been used for labeling the atoms [15]. 

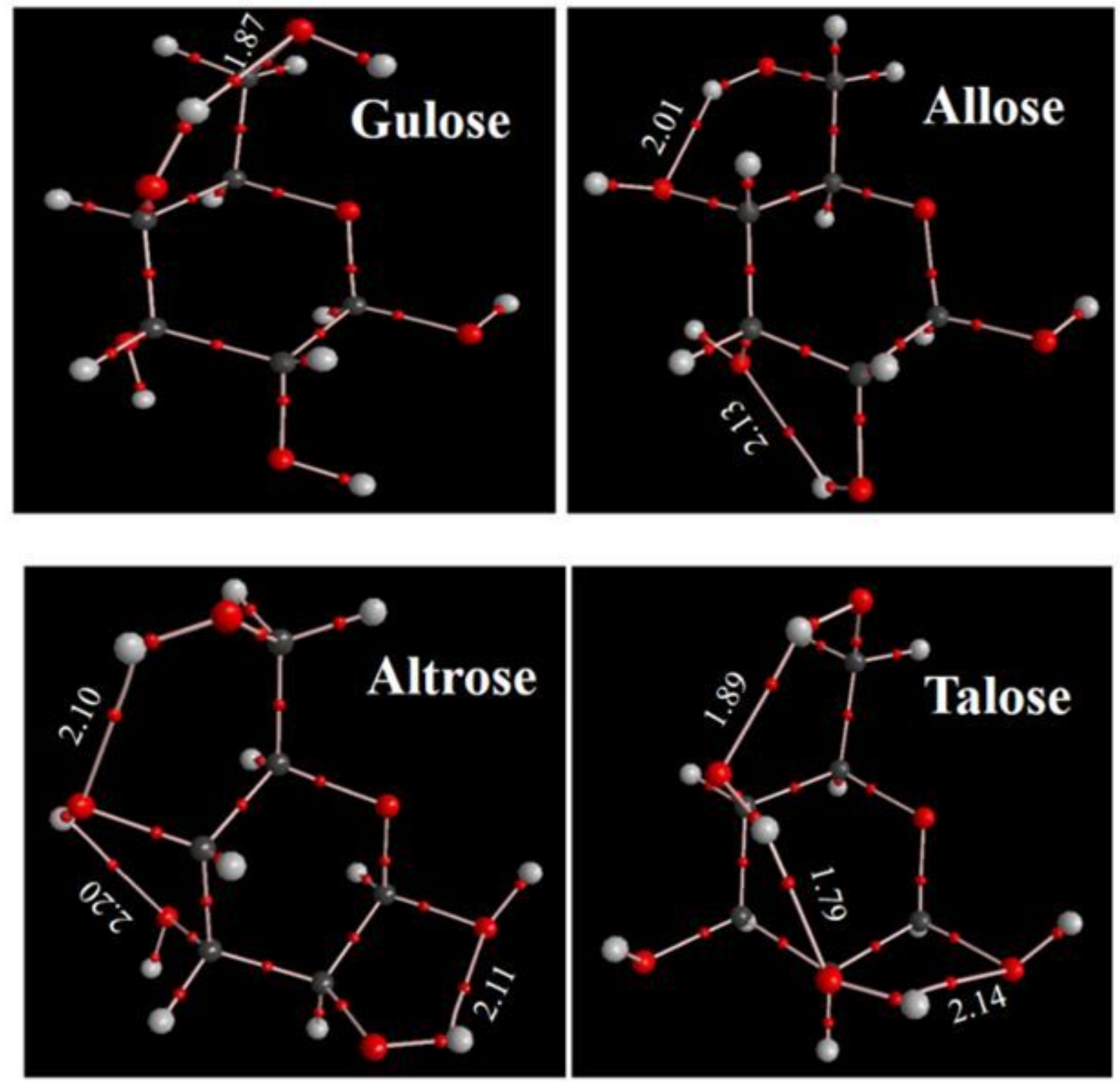

Figure 2

The optimized structure and AIM molecular graphs of gulose, allose, altrose, and talose sugars. Large circles correspond to attractors attributed to atomic positions: gray, hydrogen; black, carbon; and red, oxygen. Small circles are attributed to critical points: red, bond critical point (BCP). 

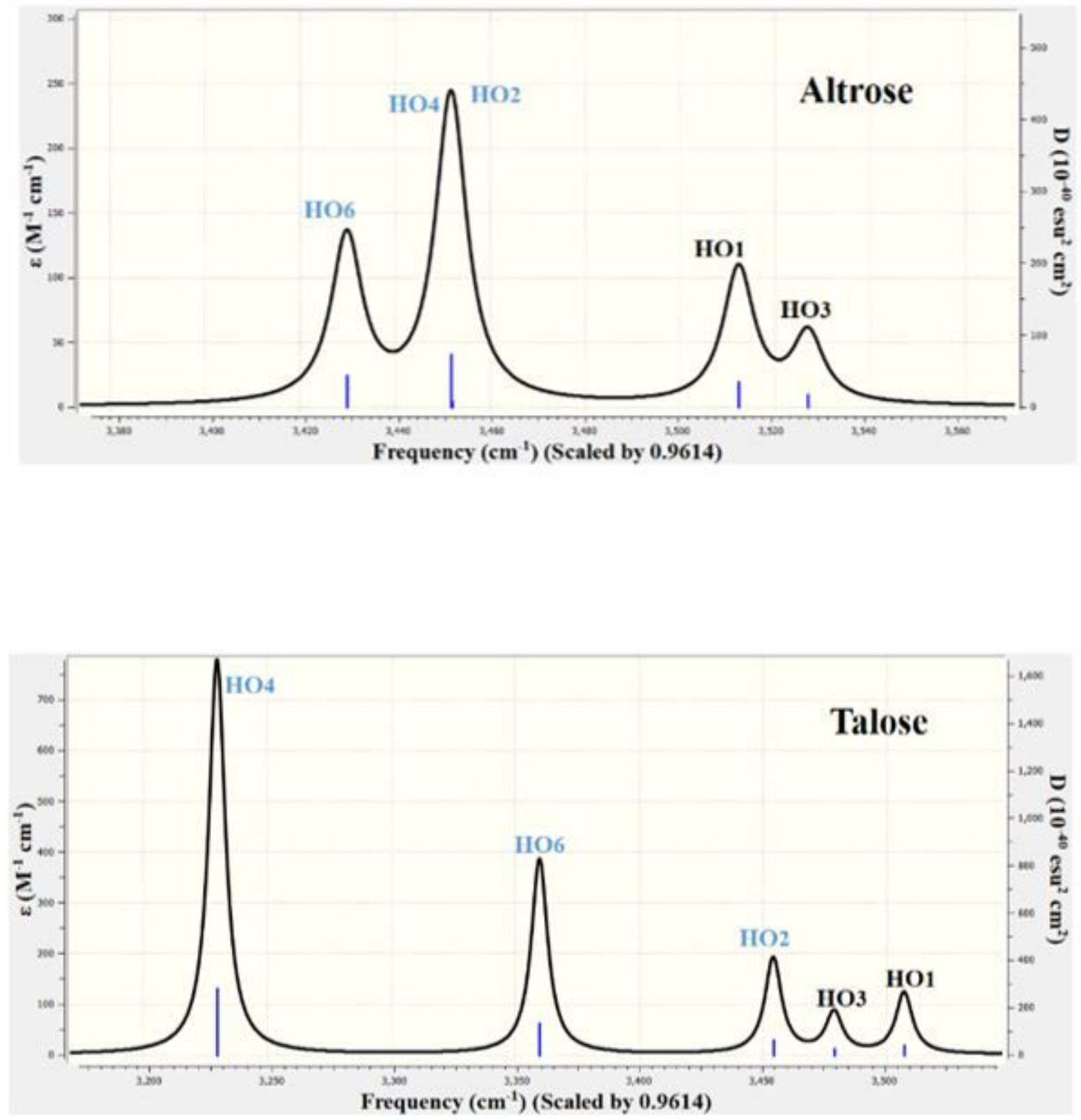

Figure 3

Theoretical FT-IR spectra by B3LYP/6-31G* method for gulose, allose, altrose, and talose. Free hydroxyl groups illustrated with black color whereas blue colors are intramolecular $\mathrm{H}$-bonds that were shifted to low frequencies. 